\title{
Fetal Effects of Epidermal Growth Factor Deficiency Induced in Rats by Autoantibodies against Epidermal Growth Factor
}

\author{
LASSE RAABERG, EBBA NEX $\varnothing$, PER E. J $\emptyset$ RGENSEN, STEEN SEIER POULSEN, AND MATYAS JAKAB \\ Institute of Medical Anatomy, Department B, The Panum Institute, Blegdamsvej 3, DK-2200 Copenhagen \\ [L.R., S.S.P.]; Department of Clinical Chemistry, Central Hospital, DK-3400 Hillerød [L.R., E.N., M.J.]; \\ Department of Clinical Biochemistry, KH, University Hospital of Aarhus, DK-8000 Aarhus C [E.N., \\ P.E.J.]; and Department of Surgery A, Central Hospital, DK-3400 Hillerød, Denmark [M.J.]
}

\begin{abstract}
We have used rats with epidermal growth factor (EGF) autoantibodies to study the role of EGF deficiency during perinatal development. The study was focused on organs known to contain EGF or its receptor. Compared with controls, the offspring of autoimmune rats had a higher perinatal mortality and a lower birth weight. The weight of the lungs was particularly low in the offspring of EGF-immunized rats, and morphologically the lungs from the surviving pups seemed atelectatic and had alveolar duct dilatation, which indicates mild respiratory distress syndrome. Judged from immunohistochemical studies, the amount of surfactant protein-A was decreased, suggesting a delayed lung maturation. The offspring of EGF-immunized rats had dry and wrinkled skin. The skin was thin and the hair follicles were immature. This suggests a role for EGF in the growth and development of the skin. The liver/body weight ratio was lower in pups from EGF-immunized rats. This difference was, however, not significant $(p=0.07)$, but flow cytometric analyses showed a significantly lower proportion of the liver cells from newborn EGF-deficient pups to be in S-phase and indicated that these cells were larger than liver cells from con-
\end{abstract}

\section{ABSTRACT}

trols. To study possible alterations in EGF binding, ${ }^{125}$ I-EGF was injected i.v. in newborn rats. ${ }^{125}$ I-EGF bound in all the organs investigated. The binding is listed in decreasing order: liver, gut, skin, kidney, and lungs. In the pups from EGF-immunized rats, the lungs and the skin bound a significantly higher amount than the controls. This could represent an upregulation of the EGF receptor in response to the lack of EGF. Postnatally, the pups from EGF-immunized mothers grew faster and were on par with controls within $1 \mathrm{wk}$. We found no differences concerning tooth eruption, ear opening, and eye opening. In extension of present knowledge concerning the tissue localization of EGF and its receptor and concerning the pharmacologic effects of EGF, our study demonstrates an effect of EGF deficiency. This supports a role for EGF in the epigenetic regulation of the development of the lungs, the skin, and the liver. (Pediatr Res 37: 175-181, 1995)

EGF, epidermal growth factor

SP-A, surfactant protein A

TGF- $\alpha$, transforming growth factor- $\alpha$
The epigenetic regulation of fetal and neonatal development is assumed to take place within a milieu of growth factors. This hypothesis is mainly deduced from the localization of growth factors and growth factor receptors and from studies of their pharmacologic effects. Limited information is available about the effects of growth factor deficiency. Based on studies in which EGF has been injected into the mother, the fetus, or the neonate, EGF is believed to be involved in the development of the integument $(1,2)$, the lungs $(3,4)$, the liver $(5)$, and the digestive tract (6). At present it has not been established whether these effects reflect a physiologic or a pharmacologic role of the peptide. One of the difficulties faced is that EGF is produced in multiple organs.

Received December 28, 1993; accepted September 1, 1994.

Correspondence: Lasse Raaberg, M.D., Ph.D., Institute of Medical Anatomy, Dept. B, The Panum Institute, University of Copenhagen, DK-2200 Copenhagen N, Denmark.

Supported by the Danish Cancer Research Foundation, the Danish Research Council (12-9312), the Boel Foundation, and the Nordisk Insulin Foundation Committee.
Because of this, the induction of EGF deficiency is complicated. A similar problem has been solved for another peptide, nerve growth factor, by induction of autoimmunity against this peptide. Using autoimmunity toward nerve growth factor, Gorin and Johnson (7) demonstrated an inadequate development of the sympathetic nervous system. Inspired by this work, we have developed rats with autoimmunity against EGF (8).

In our study, we have investigated the effects of EGF deficiency during fetal and neonatal development. Because EGF is supposed to act locally during development, we have focused our investigations on organs that contain EGF or its receptor, that is the lungs, kidneys, gut, liver, skin, and placenta $(9,10)$.

\section{METHODS}

Induction of antibodies. Autoimmunity was induced in female Wistar rats (Pan:Wist). The antibodies were induced as 
previously described by one injection of Freund's complete adjuvant mixed with $1 \mathrm{nmol}$ of EGF purified from rat submandibular glands and three booster injections with $0.5 \mathrm{nmol}$ of rat EGF and Freund's adjuvant (8). Rats with serum that, in a dilution of 1:10, bound more than $60 \%$ of added EGF after the fourth immunization were included.

Effects in newborn rat. A total of 50 rats were immunized with rat EGF for these experiments; 34 of these developed an antibody production above the inclusion limit. For controls, 20 rats were immunized with Freund's adjuvant and saline and five rats were immunized with human recombinant TGF- $\alpha$ (kindly donated by Triton, Alameda, CA). Furthermore, 10 nonimmunized rats were used for controls. The rats were mated with nonimmunized male rats, and the number of rats completing pregnancy, the number of pups, the perinatal mortality (death within $48 \mathrm{~h}$ ), the birth weight of the pups, and the postnatal developmental features such as incisor eruption, opening of the ear canal, and opening of the eyes were observed as well as the growth rate. One pup from each litter was killed at $\mathrm{d} 1,7,14$, and 21, and the liver, lung, kidneys, and gut were weighed. These organs as well as abdominal skin were fixed for histologic evaluation. Flow cytometric analyses of the livers were performed, and the metabolism of i.v. injected EGF was studied in pups from EGF-immunized mothers and in pups from controls. Because there was no difference between the three control groups, the data from these groups were pooled.

Effects in rat fetus. Nineteen EGF-immunized and 20 saline-immunized rats from the above series were given a booster dose and mated $14 \mathrm{~d}$ later. The day a plug was found was considered $\mathrm{d} 1$. On the $21 \mathrm{st} \mathrm{d}$ of gestation, the amniotic fluid was drained and the fetuses were weighed. The placenta, liver, lungs, kidneys, and gut were weighed and fixed for histologic evaluation. Additional skin from the abdominal wall was fixed for histologic evaluation.

Antibodies. After the fourth immunization, $400 \mu \mathrm{L}$ of blood were collected. The ability of the sera to bind ${ }^{125} \mathrm{I}-\mathrm{EGF}$ was assessed as previously described (8). The binding capacity was also determined in amniotic fluid collected on the 21 st $\mathrm{d}$ of gestation. Because it was not possible to obtain enough blood from fetuses and newborn rats for determination of the binding capacity, we used homogenates of the blood-filled livers. The livers from immunized and control pups were homogenized in $5 \mathrm{~mL}$ of PBA [0.1 M phosphate buffer, $\mathrm{pH} 8.0,0.1 \%$ human albumin (Behringwerke, Germany)] per $g$ tissue. A total of 2000 KIU Trazylol (aprotinin, Bayer, Germany) was added per $\mathrm{mL}$ of PBA. The homogenate was centrifuged for $30 \mathrm{~min}$ at $17500 \times g$. The supernatant was used for determination of the EGF-binding capacity. The nonspecific binding was assessed by adding PBA instead of liver extract.

Transmission of ${ }^{125}$ I-EGF. Approximately $5 \times 10^{6} \mathrm{cpm}(10$ $\mathrm{pmol}$ ) were injected into the inferior vena cava of 20 nonimmunized pregnant rats at the 21 st $d$ of gestation. Fifteen min after the injection, the uterine vessels were clamped, and the placentas and the fetuses were removed and counted in a $\gamma$-counter. For characterization of the radioactivity in the fetuses, these were homogenized and the supernatants were applied to a $1.1 \times 45-\mathrm{cm} \mathrm{S-200} \mathrm{Sephacryl} \mathrm{column} \mathrm{that} \mathrm{was}$ calibrated and run in PBA as previously described (11). Frac- tions of $0.6 \mathrm{~mL}$ were collected, and the radioactivity in the fractions was determined.

Binding of ${ }^{125}$ I-EGF by placenta membranes. Membranes were prepared as previously described (12), and the protein concentration was adjusted to $10 \mathrm{mg} / \mathrm{mL}$. The membranes were incubated with $100 \mu \mathrm{L}$ of ${ }^{125}$ I-EGF (approximately $300 \mathrm{fmol}$ ) overnight. Bound tracer was separated from unbound by highspeed centrifugation $(17500 \times g$ for $30 \mathrm{~min})$ of the membranes. High-speed centrifugation was used instead of filtration because it permitted the use of an increased amount of membranes in the binding assay. The pellet was counted in a $\gamma$-counter.

Metabolism of ${ }^{125}$ I-EGF. Two newborn pups from each of nine EGF-immunized litters and from 14 control litters were anesthetized by intraperitoneal injections of Brietal (methohexital, Eli Lilly, Indianapolis, IN), and the abdominal wall was cut open. Approximately $200000 \mathrm{cpm}$ of ${ }^{125}$ I-EGF $(0.4$ pmol) were injected into the inferior vena cava by a micropipette. Preliminary studies showed that the tracer was almost absent from the blood after $2 \mathrm{~min}$. Two min after the injection, the pup was decapitated and the liver, lungs, gut, kidneys, and skin were excised and counted in a $\gamma$-counter.

${ }^{125} \boldsymbol{I}-\boldsymbol{E} \boldsymbol{G} \boldsymbol{F}$. EGF was purified from rat submandibular glands and iodinated as described using the chloramine-T method (10). The sp act was approximately $500000 \mathrm{cpm}$ per pmol of EGF.

Protein determination. The protein concentration was determined using the Pierce bichinchonic acid method (13).

Histologic examinations. The tissues were fixed by immersion in ice cold Bouin's fluid without acetic acid for $1 \mathrm{~h}$ and postfixed for at least $24 \mathrm{~h}$ in $70 \%$ ethanol. The tissues were then embedded in paraffin and cut into $5-\mu \mathrm{m}$ sections. The sections were stained with periodic acid-Schiff, aurantia, and hematoxylin or were investigated immunohistochemically using two EGF antisera, ab 3123 (14) and ab 1589 (15). The immunoreaction was visualized by the peroxidase-antiperoxidase technique as previously described (16). For evaluation of the morphology of the lungs, photomicrographs were taken from the most normal-looking part of each section. The photomicrographs were analyzed by a computer as described below. The thickness of the skin (the thickness of the dermis and the epidermis) was measured on photomicrographs. The measured thickness was recalculated to absolute thickness using the magnification. All photomicrographs were taken and evaluated by blinded investigators.

Computer analyses of lung sections. The $10 \times 10 \mathrm{~cm}$ areas from the above-mentioned photomicrographs (final magnification $\times 80$ ) of lung sections were scanned into a Macintosh Quadra 700 computer and analyzed by the computer program Image ver. 1.41, written by Wayne Rosband, National Institutes of Health, Bethesda, MD. Using this program, the scanned pictures were binary transformed, and the air-filled areas were measured and calculated as a fraction of the total area. The number of air filled spaces in the analyzed area was also counted by the computer.

Surfactant immunohistochemistry. The sections were stained with a rabbit anti-human SP-A, kindly donated by Jeffrey A. Whitsett, University of Cincinnati, Cincinnati, $\mathrm{OH}$. 
The immunoreaction was visualized using a biotinylated secondary swine antiserum (E353, Dakopatt, Glostrup, Denmark) and streptavidin-Texas Red as the third layer according to the manufacturer's instructions. To perform a semiquantitative analysis, the sections were stained with different dilutions of the primary antiserum (1:100-1:1600) and the highest dilution with a positive immunoreaction was noted.

Flow cytometry. Liver cells from seven pups from immunized rats (different litters) and from five newborn pups from saline-immunized rats (different litters) were prepared with modification of the method used by Guguen-Guillouzo et al. (17). In brief, the livers were cut in small fragments and washed three times with $10 \mathrm{mM} \mathrm{N}$-2-hydroxyethylpiperazine$N^{\prime}$-2-ethanesulfonic acid buffer, $\mathrm{pH} 7.6$, and incubated in $0.05 \%$ collagenase (type I, Sigma Chemical Co., St. Louis, $\mathrm{MO})$ in a $100 \mathrm{mM} N$-2-hydroxyethylpiperazine- $N^{\prime}-2$ ethanesulfonic acid buffer, $\mathrm{pH} 7.5$, for $10 \mathrm{~min}$ at $37^{\circ} \mathrm{C}$. The digestion was repeated two times. The first supernatant was discharged because it contained mainly nonparenchymal cells and debris. The second and the third supernatant were collected and centrifuged at $50 \times g$ for $2 \mathrm{~min}$. The cells were washed three times with PBS (0.04 M PBS, pH 7.4). The cell suspension (containing approximately 200000 cells in $0.3 \mathrm{~mL}$ ) was stained for $30 \mathrm{~min}$ in $0.6 \mathrm{~mL}$ of staining solution that contained $50 \mu \mathrm{g} / \mathrm{mL}$ propidium iodide (Sigma), $0.1 \mathrm{mg} / \mathrm{mL}$ RNase (Sigma), $0.01 \%$ Nonidet P-40 (Fluka, Buchs, Switzerland), and $0.05 \mathrm{mM}$ EDTA in Dulbecco's PBS. Finally, the cells were filtered through a 30- $\mu$ m nylon mesh (Scrynel HC, New York, NY). The cells were analyzed on an EPICS Profile flow cytometer (Coulter Electronics, Hialeah, FL). The forward scatter distribution of the cells and the percentage of cells in $\mathrm{S}$ phase were calculated by the EPICS cytology software.

Statistics. Results are given as median with range in parentheses. The Mann-Whitney U test and Fisher's exact test were used. A probability of less than $5 \%$ was considered significant.

\section{RESULTS}

The rate of completed pregnancies was the same among immunized rats and control rats (12/15 versus $12 / 15)$, and the median number of pups per litter was 13 (range four to 17) in both groups. Antibodies against EGF were present in the amniotic fluid and in the supernatants of liver homogenates from fetuses and from 7-d-old pups. No specific EGF-binding capacity was present in amniotic fluid and supernatants from controls. Upon injection of ${ }^{125}$ I-EGF into nonimmunized pregnant rats, only $0.3 \%$ of the radioactivity was transferred to the fetuses after $15 \mathrm{~min}$. As judged from gel filtration, all the transferred radioactivity was free ${ }^{125} \mathrm{I}$ (data not shown).

The perinatal mortality was significantly higher in litters from EGF-immunized rats than in the control litters $(40 / 169$ versus 1/137; $p<0.0001$ ). The offspring of EGF-immunized mothers had dry and wrinkled skin (Fig. 1) and a significantly lower birth weight than offspring of control rats (5.5 versus 6.3 g; $p<0.01$ ) (Table 1).

Because the pups from the EGF-immunized rats had a lower birth weight, the weight of the liver, lungs, gut, and kidneys was calculated relative to the body weight. The lung/body

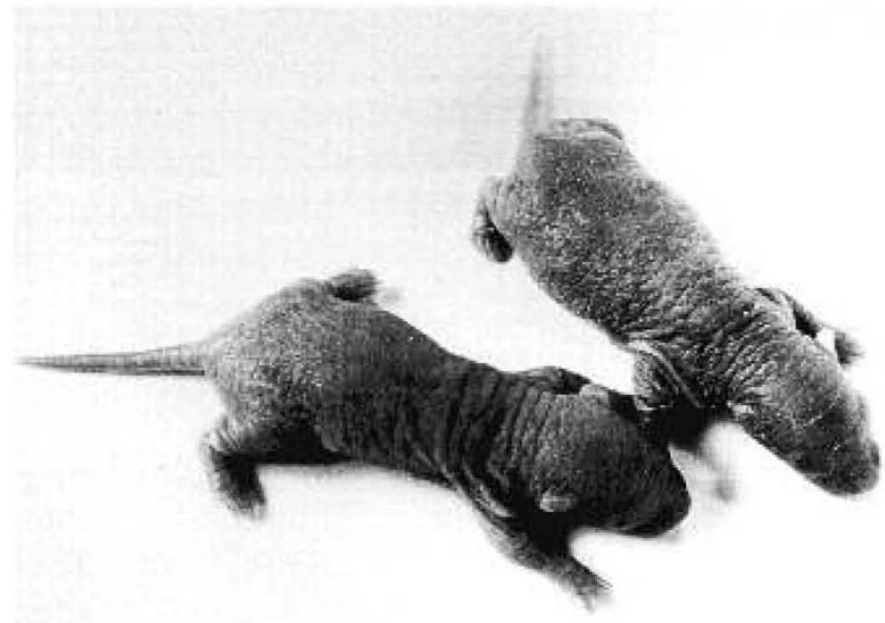

Figure 1. Two 3-d-old pups from a control rat (bottom) and an EGFimmunized rat (top). The pup from the EGF-immunized rats has dry and wrinkled skin compared with the control.

Table 1. Effect of EGF deficiency on body weight, lung/body weight ratio, and liver/body weight ratio

\begin{tabular}{lccc}
\hline & $\begin{array}{c}\text { Body } \\
\text { weight } \\
(\mathrm{g})\end{array}$ & $\begin{array}{c}\text { Lung/body } \\
\text { wt ratio } \\
(\%)\end{array}$ & $\begin{array}{c}\text { Liver/body } \\
\text { wt ratio } \\
(\%)\end{array}$ \\
\hline EGF immunized $(n=12)$ & 5.5 & 1.66 & 3.83 \\
& $(4.6-7.1)$ & $(1.45-1.87)$ & $(3.26-4.98)$ \\
Controls $(n=12)$ & 6.3 & 1.83 & 4.35 \\
Level of significance & $(5.3-7.5)$ & $(1.61-2.04)$ & $(3.77-5.66)$ \\
& & & $\mathrm{NS}$ \\
& $p<0.01$ & $p<0.005$ & $(p=0.07)$ \\
\hline
\end{tabular}

The organ/body weight ratio was used because the body weight was lower in the immunized pups. The lung/body weight was significantly lower in EGF-immunized pups.

weight ratio was significantly lower in the EGF-immunized group than in the controls (Table 1), and also the liver/body weight ratio appeared to be lower in the immunized group than in the controls, but this difference was not significant ( $p=$ 0.07 ) (Table 1). No differences were seen between gut/body weight and kidney/body weight ratio.

Judged by morphologic studies, the skin from newborn EGF-immunized rats was thinner than the skin from newborn control pups $(0.31$ versus $0.44 \mathrm{~mm} ; p<0.005)$, and furthermore the hair follicles were immature compared with controls (Fig. 2).

The morphology of the lungs from living newborn pups from the EGF-immunized mothers was heterogeneous compared with the lungs from control pups. There were areas that appeared atelectatic and displayed alveolar duct dilation (Fig. 3). Computer analyses of the lungs measured the proportion of the picture comprising air-filled spaces. The air-filled fraction comprised $0.73(0.54-0.81)(n=6)$ in lungs from controls and $0.47(0.37-0.62)(n=7)$ in pups from EGF-immunized mothers $(p<0.03)$. The numbers of air-filled spaces in the pictures were counted. Control lungs contained a median of 179 (108289) air spaces and the lungs from EGF-immunized pups contained 459 (216-628). To further investigate lung matura- 

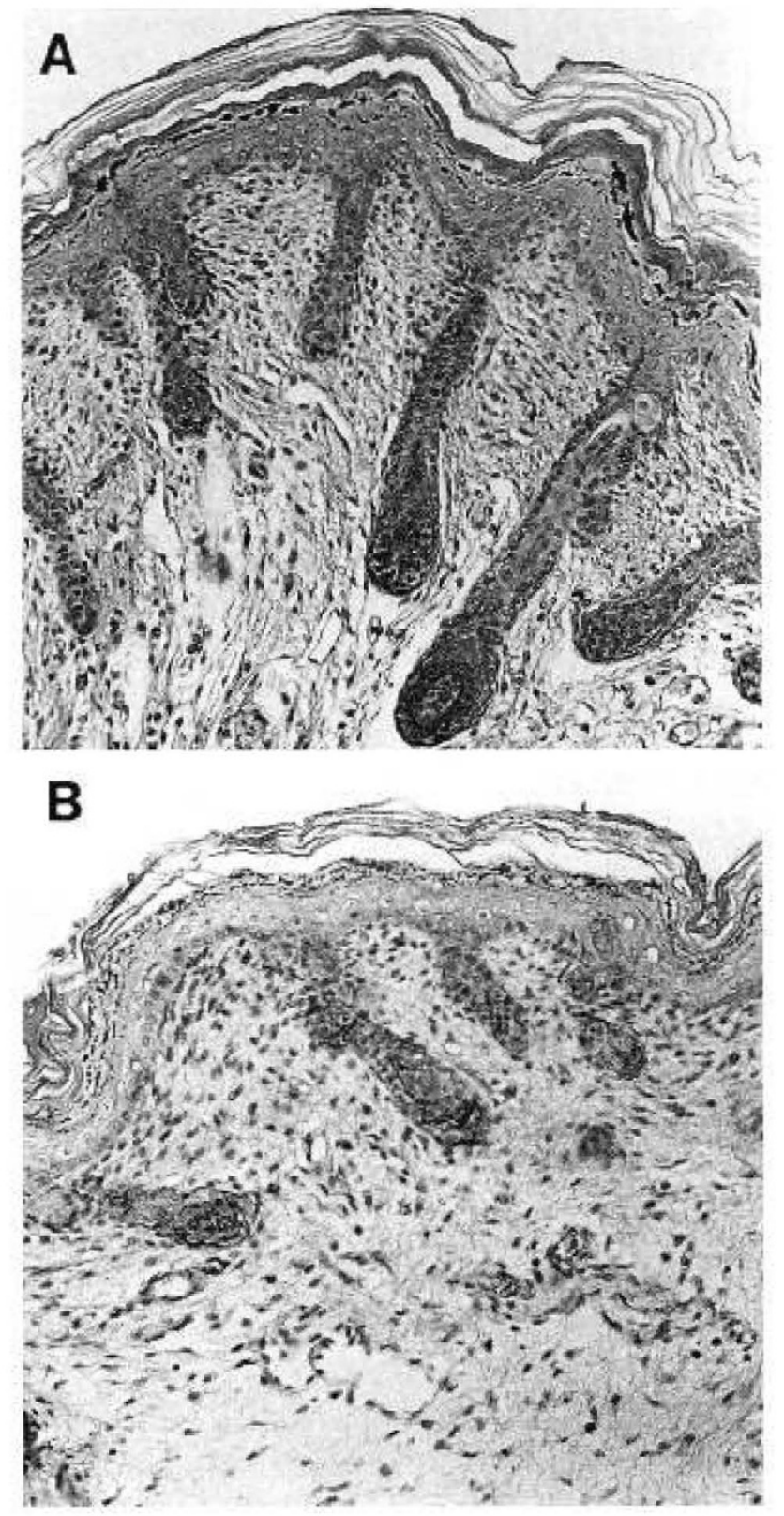

Figure 2. Histologic sections from the skin. $a$ is from a control pup and $b$ is from an EGF-deficient pup. The EGF-deficient pups had significantly thinner skin (epidermis and dermis) and poorer development of the hair follicles. Periodic acid-Schiff, aurantia, and hematoxylin stained. Magnification $\times 118$.

tion, we performed immunohistochemistry for SP-A. The immunoreaction was present in type II pneumocytes, on the alveolar surface, and in cells of the bronchi and bronchioli (Fig. 4). When the primary antiserum was diluted 1:800, most of the lungs from control pups had positive staining (eight of 12), whereas only two of 12 of the EGF-deficient pups had positive immunostaining at this dilution $(p<0.05)$. The staining was absent in most lungs when the antiserum was diluted 1:1600. Hence the staining for SP-A was stronger in the lungs from newborn controls than in the lungs of newborn pups from EGF-immunized rats. The distribution and staining intensity of EGF-reactivity in the lungs, kidneys, and gut appeared alike in EGF-immunized rats and controls. No EGF immunoreactivity was seen in the liver or the skin.
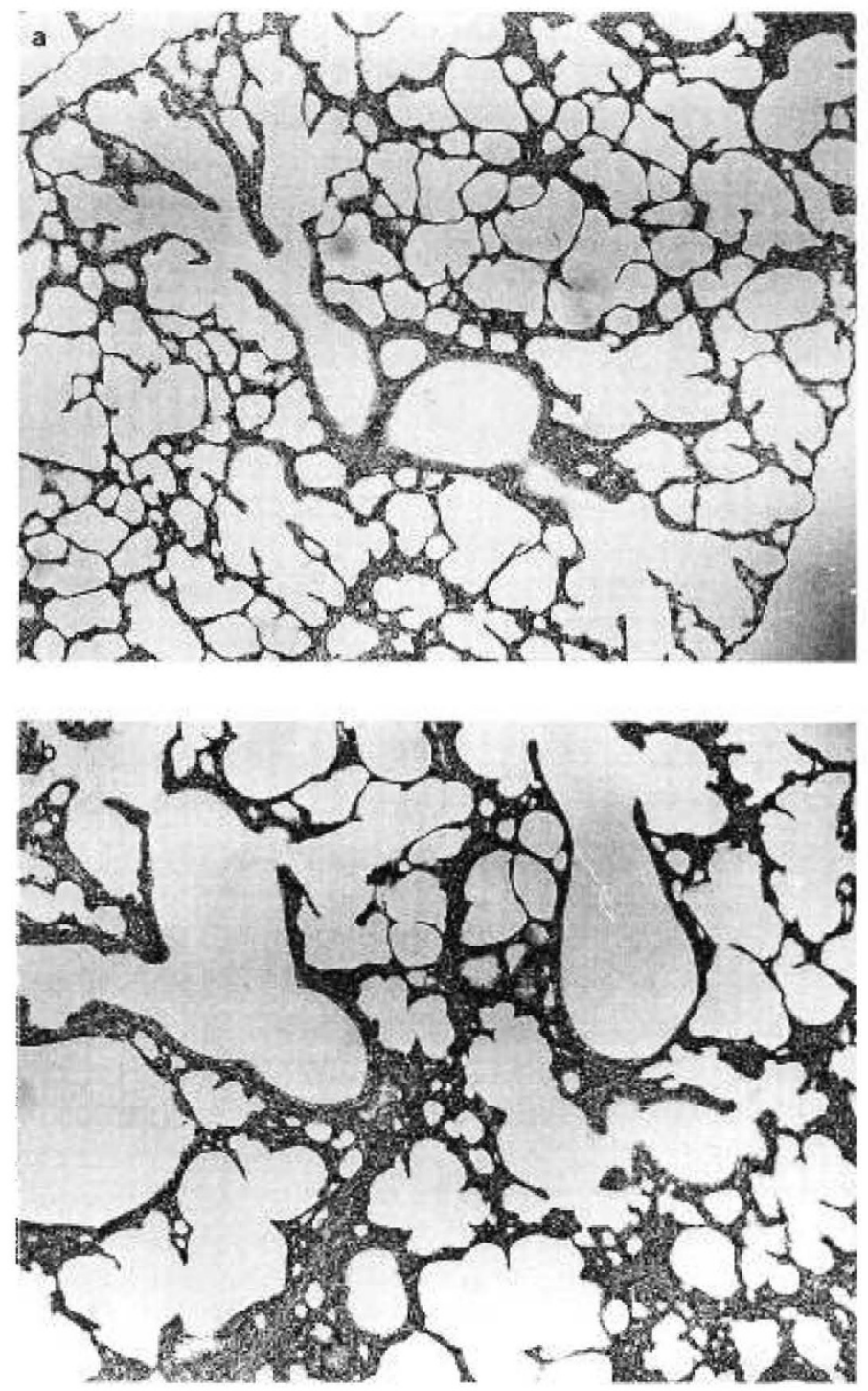

Figure 3. Lungs from newborn living pups. $a$, The lungs from a pup from a control mother. $b$, The lungs from an EGF-deficient pup, showing a more heterogeneous picture consistent with atelectasis and compensatory alveolar duct dilation in the pups from EGF-immunized rats. Periodic acid-Schiff, aurantia, and hematoxylin stained. Magnification $\times 80$.

Flow cytometry analyses of liver cells from newborn pups showed that $9.5 \%(7.5-11.5 \%)$ of the liver cells from immunized rats were in the S phase compared with $18.5 \%$ (14.1$24.3 \%)$ of the liver cells from control pups $(p<0.003)$. When the forward scatter measurements from the immunized rats were pooled and compared with the pooled results from the controls, there was a tendency toward a larger cell size in the pups from EGF-immunized rats (Fig. 5).

The distribution of ${ }^{125}$ I-EGF injected into the newborn pups was studied in five organ systems known to possess EGF receptors. The liver contained the highest amount of radioactivity, followed in decreasing order by the gut, the skin, the kidneys, and the lungs. This distribution pattern was alike in the two groups, but in the EGF-immunized group the lungs and the skin contained significantly more radioactivity than the controls (Fig. 6). The amount of EGF in the liver was insignificantly lower in the pups from EGF-immunized mothers. 

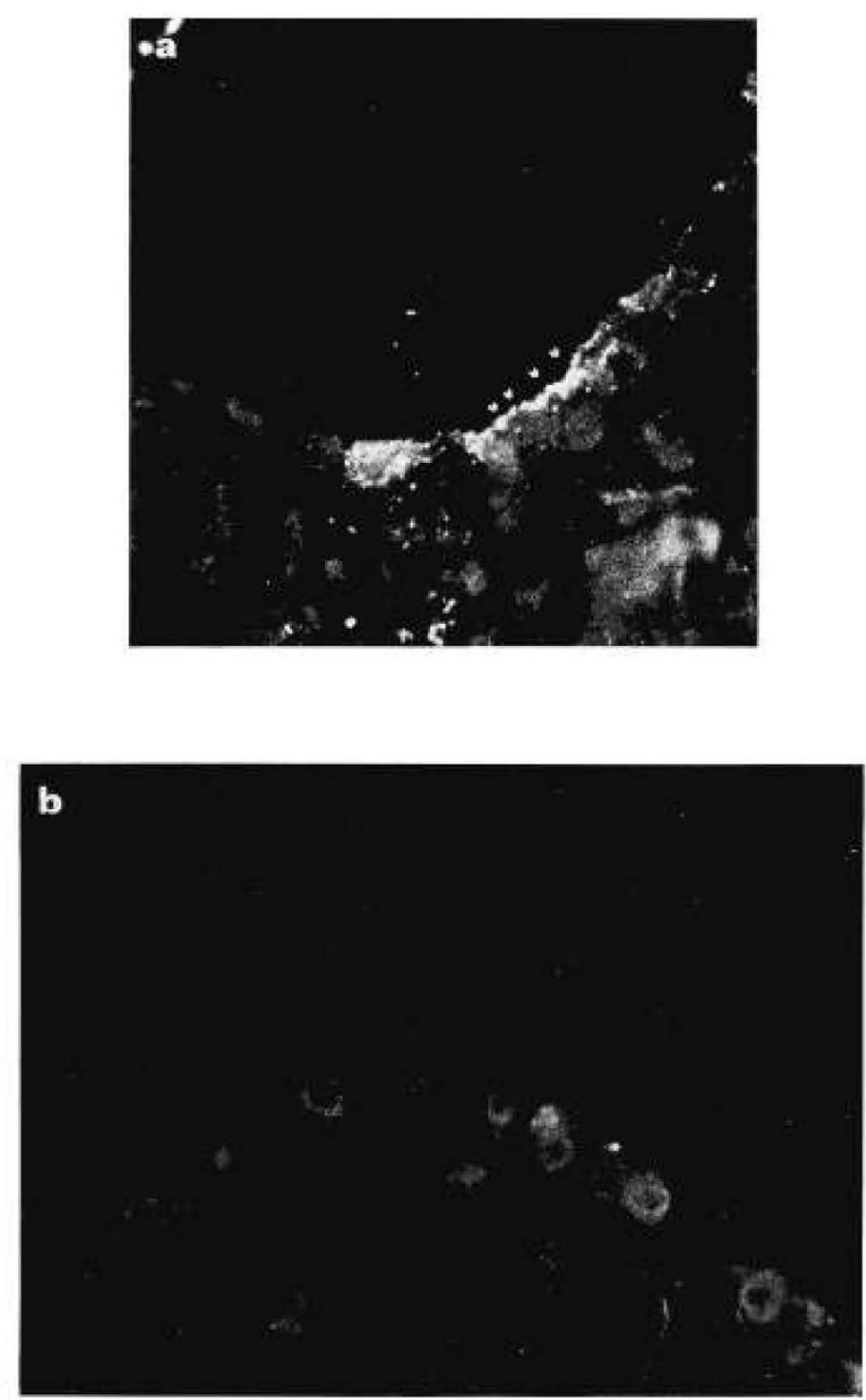

Figure 4. Immunohistochemical localization of SP-A in the lungs from newborn rats. The immunoreaction was present in type II pneumocytes and on the alveolar surface $(a)$. Magnification $\times 540$. The immunoreaction was also seen in single cells in the conducting airways $(b)$, most likely the Clara cells. Magnification $\times 720$; antibody dilution 1:200.

The EGF-immunized fetuses studied on the 21st $\mathrm{d}$ of gestational (birth at d 22-23) did not show any differences in median number per litter (11.5 versus 10$)$ body weight ( 4.1 versus 3.9 $\mathrm{g}$ ) or weight of the placenta ( 0.61 versus $0.67 \mathrm{~g})$, the liver $(0.30$ versus $0.27 \mathrm{~g})$, the gut $(0.15$ versus $0.11 \mathrm{~g})$, the kidneys ( 0.03 versus $0.03 \mathrm{~g}$ ), or the lungs ( 0.13 versus $0.12 \mathrm{~g}$ ) compared with control-immunized fetuses.

Placenta membranes from immunized and control fetuses were prepared, and the binding of ${ }^{125} \mathrm{I}$-EGF was estimated. No difference was seen in the binding capacity. Median bound fraction was $0.25(n=3)$ versus $0.25(n=3)$.

During the first week postnatally, the EGF-immunized pups grew faster than the controls and were on a par with the controls after $1 \mathrm{wk}$. The differences in organ weight disappeared during the first week. Furthermore, the day of incisor eruption, the day of ear canal opening, and the day of eye opening were the same.

\section{Fraction}

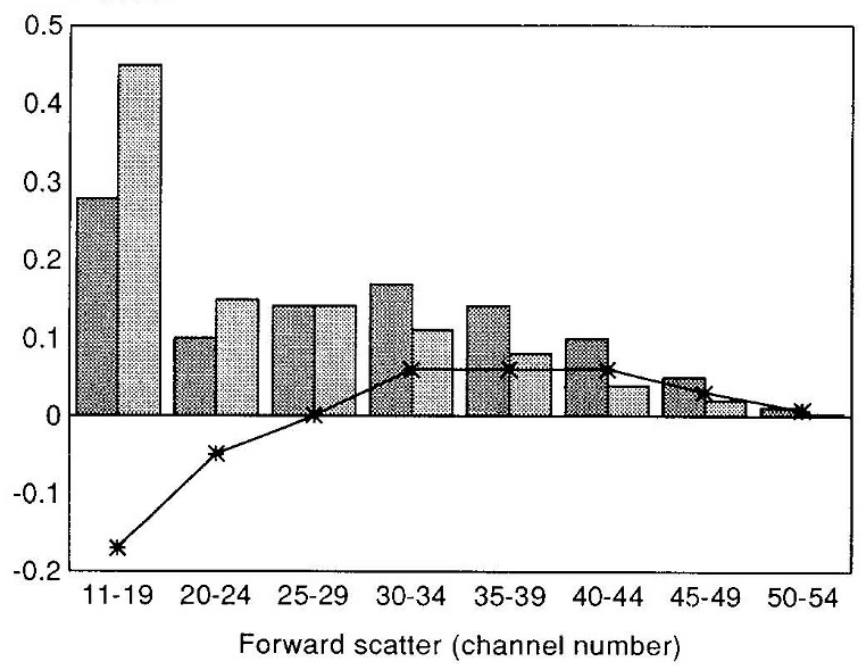

Figure 5. Forward scatter distribution of the pooled data from immunized and control pups. This indicates that the hepatocytes from controls are smaller than hepatocytes from EGF-deficient pups. $x$ axis: channel number; $y$ axis: percentage of total cell number; curve: difference between columns. Dark columns, EGF-immunized pups; light columns, controls.

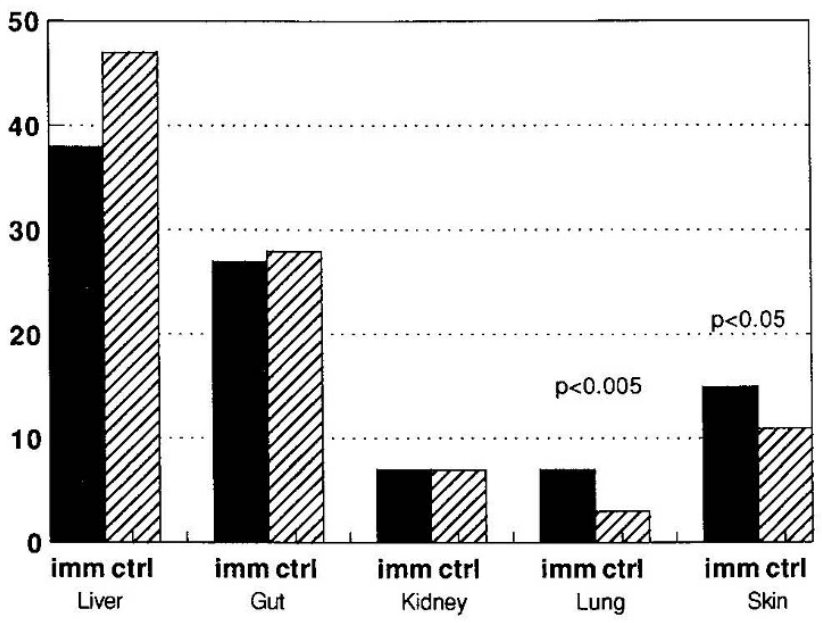

Figure 6. Metabolism of i.v. injected ${ }^{125}$ I-EGF in newborn pups from EGFimmunized ( $\mathrm{imm}$ ) and control-immunized pups $(\mathrm{ctrl})$. There was a significantly higher amount of tracer in the skin and the lungs of pups from EGF-immunized rats. There was a nonsignificantly lower uptake in the liver of these pups. The changed distribution might imply compensatory adjustments in the distribution of the EGF receptor in response to EGF deficiency.

\section{DISCUSSION}

It is now widely postulated that EGF participates in the epigenetic regulation of organ growth and differentiation during fetal and neonatal development. However, the evidence supporting a developmental role for EGF has largely been inferred from detection of EGF and EGF mRNA, and from pharmacologic studies. We use EGF autoimmunity to induce EGF deficiency and provide further evidence in support of the hypothesis that EGF serves specific epigenetic regulatory functions during fetal and neonatal development.

We believe that the model can be used to study functional EGF deficiency due to the following arguments. The rats with EGF autoimmunity were able to become pregnant and to complete the pregnancies, and the antibodies against EGF were transferred to 
the fetuses and the newborn. The antibodies inhibit the binding of EGF to its receptor by more than $90 \%$ (8).

We found no difference between our control groups: nonimmunized rats, rats immunized with human TGF- $\alpha$, and rats immunized with saline and Freund's adjuvant. This supports the assumption that observations made about rats with antibodies against EGF represent an effect of EGF deficiency. The reason for not seeing any effects of TGF- $\alpha$ immunization might be that TGF- $\alpha$ acts earlier in fetal development, at a time when no antibodies are transferred from mother to fetus (18); alternatively, the induced antibodies might be unable to recognize rat TGF- $\alpha$, inasmuch as we used synthetic human TGF- $\alpha$ as immunogen.

We did not find any transmission of ${ }^{125}$ I-EGF to the fetus 15 min after the injection. This in accordance with the findings of DiAugustine et al. (19) in mice and suggests that the fetus depends on its own EGF production. The three observations taken together indicate that the model studies effects of functional EGF deficiency.

Our most dramatic observation was the increase in perinatal mortality. This is in agreement with a study from Tsutsumi and Oka (20), who described an increased perinatal mortality in mice upon pregestational sialoadenectomy. This decreases the level of circulating EGF in the mouse. The mortality was further increased by injection of heterologous EGF antiserum during pregnancy. The authors did not suggest any specific cause of death. In our study, the surviving pups from EGF-immunized mothers appeared dysmature and had a lower birth weight than the pups from control rats. This difference is not likely to be caused by poorer nourishment from the mother because no differences were observed in the weight, the histologic appearance, or the EGFbinding capacity of the placenta. There was no difference between the groups at gestational $\mathrm{d} 21$, which indicates that the effect of EGF relates to the very last part of the pregnancy, an observation that is in accord with the late initiation of the EGF synthesis in the rat fetus (21). Postnatally, we found an increased growth rate in the EGF-deficient pups. This could be a counterpart to the previously described growth delay in EGF-treated newborn sucklings (22).

The effect of alterations in the level of EGF on the birth weight is ambiguous. Most authors find no effect of EGF injections $(3,4,23)$, but an increased body weight has been reported (24). Tsutsuma and Oka (20) demonstrated that EGF deficiency decreased the weight of the fetuses, which is in accordance with our study.

From a functional point of view, an organ-specific pharmacologic effect of EGF indicates the presence of the EGF receptor. Because EGF is supposed to act in a paracrine or autocrine manner, EGF is also likely to be found in the same organ. The organ-specific portion of our study was focused on organs known to be responsive to EGF or to contain the EGF receptor.

EGF in pharmacologic doses is able to induce functional and morphologic lung maturation in rabbit and sheep fetuses in vivo $(3,4)$ and in fetal human and mouse lungs in vitro $(25$, 26). EGF $(16)$ and its receptor $(27,28)$ are present in the lungs before birth.

In our study, we found smaller and immature lungs and a decreased staining for SP-A in the EGF-autoimmune and thereby EGF-deficient pups. The weight of the lungs relative to the body weight was lower in pups from immunized mothers at the time of birth; furthermore, the pups from immunized mothers displayed lung changes in accordance with mild respiratory distress syndrome, i.e. small partially collapsed alveoli and compensatory alveolar duct dilation. This was further substantiated by the computer analyses of the lungs, which showed that the amount of air was greater in the lungs from control pups, whereas the number of air-filled spaces per picture was higher in lungs from EGF-deficient pups. SP-A immunoreactivity was studied as an indicator of lung maturity. The immunoreaction for SP-A was found in the three known localizations for SP-A, namely in type II pneumocytes, on the alveolar surface, and in the Clara cells (29). The immunoreaction was reduced in the lungs from EGF-immunized pups. SP-A is a marker of the surfactant production, which plays a central role in the adaptation to extrauterine life (for review see Ref. 30).

We have recently shown that rat type II pneumocytes in primary culture possess a high molecular weight form of EGF in addition to EGF receptors capable of signal transduction in response to exogenous EGF (31), suggesting that the demonstrated regulatory effect of EGF might be mediated in a paracrine or autocrine manner.

In vitro studies also demonstrate an effect of EGF on lung development. In a study on the role of EGF in mouse lung branching morphogenesis, Warburton et al. (26) showed that EGF stimulated branching morphogenesis and that this stimulation could be blocked by tyrphostin, a receptor kinase antagonist. The finding of Whitsett et al. (25) in human fetal lung tissue in culture, showing that EGF induces SP-A production (25), indicates that EGF also plays a role in human lung development. In conclusion, this part of the study together with previous work indicates a role for EGF during lung development.

The newborn pups from the EGF-immunized mothers had dry and wrinkled skin. Histologically, the skin was thinner and the hair follicles were more poorly developed in the newborn pups from EGF-immunized mothers. EGF stimulates DNA, RNA, and protein synthesis in explants of chicken embryo skin $(32,33)$. The EGF receptor is expressed in a time- and position-restricted manner during fetal rat skin development, and the receptor expression correlates well with developmental landmarks during skin growth and hair development (34). In response to the injection of EGF, a hypertrophy of the sebaceous glands, follicular sheath, and sweat gland ducts, but a reduction in the development of the arrector pili muscles, was seen (1). Our finding of a delayed development of the epithelial components of the skin in response to EGF deficiency speaks in favor of a physiologic role for EGF during the development of the skin.

In mice with TGF- $\alpha$ gene null mutations, the skin development was affected. These mice had derangement of the skin and the hair follicles resulting in wavy hair. Furthermore, they were born with eye abnormalities including open eyelids at birth $(35,36)$. TGF- $\alpha$ is a member of the EGF-growth factor family, but the observed developmental abnormalities are not identical with our observations and might indicate that EGF 
and TGF- $\alpha$ stimulates the EGF receptor in the skin at different time points during development.

The liver weight/body weight ratio tended to be lower in the EGF-immunized group. This difference was not significant ( $p$ $=0.07$ ), but the flow cytometric evaluation showed a significantly lower proportion of the liver cells in $\mathrm{S}$ phase and the forward scatter measurements indicated a larger liver cell size in pups from EGF-immunized mothers.

Infusion of EGF in ovine fetuses (1) and injection in newborn rabbits (5) increased the liver weight. EGF stimulates DNA synthesis and cell proliferation in neonatal as well as adult rat hepatocytes in primary culture (5). However, Hoath (22) showed a decreased postnatal liver growth in neonatal rats in response to injection of EGF. The lower liver weight and the lower fraction of cells in S phase in our EGF-deficient pups speaks in favor of a growth-enhancing effect of EGF during fetal life. However, we do find accelerated growth of the liver in the EGF-deficient pups during the first week postnatally. This could be a counterpart to the decreased growth shown by Hoath (22), indicating that the in vivo actions of EGF change after birth.

To study any possible alterations in EGF receptor distribution in immunized rats compared with controls, we studied the metabolism of ${ }^{125}$ I-EGF in newborn pups. After i.v. injection of ${ }^{125} \mathrm{I}-\mathrm{EGF}$, it was found in the liver, gut, skin, kidneys, and lungs. Compared with the adult rat, the distribution pattern was different. In the adult rat, a much higher percentage of the injected EGF was found in the kidneys (10). Compared with controls, the immunized pups had a significantly higher amount of tracer in the lungs and the skin. The changed distribution in the pups from EGF-immunized mothers could indicate a mechanism by which some of the affected tissues are partially compensating for the EGF deficiency, probably by an increased number of receptors.

In conclusion, previous studies have demonstrated that EGF and its receptor are present in the fetus and the newborn and that the injection of pharmacologic doses of EGF affects the developmental clock. In our study, we have adapted an autoimmune model for the induction of growth factor deficiency to study the role of EGF during perinatal development. Using this model, we have obtained results that are in agreement with a physiologic role for EGF during development of the lungs, liver, and skin. Hence, we find it likely that EGF forms recognized by the induced antibodies are epigenetic regulators involved in the perinatal development.

Acknowledgments. The authors thank Lotte Bakhøj, Kamma Velin, and Mette Wolf Madsen for their excellent technical assistance and Grazyna Hahn for her photographic assistance.

\section{REFERENCES}

1. Thorburn GD, Waters MJ, Young IR, Dolling M, Buntine D, Hopkins PS 1981 Epidermal growth factor: a critical factor in fetal maturation? In: Elliot $\mathrm{K}$ (ed) The Fetus and Independent Life. Ciba Foundation Symposium 86. Pitman, London, pp 172-198

2. Cohen S 1987 Epidermal growth factor. In Vitro Cell Dev Biol 23:239-245

3. Sundell HW, Grey ME, Serenius FS, Escobedo MB, Stahlman MS 1980 Effects of epidermal growth factor on lung maturation in fetal lambs. Am J Pathol 100:707-726
4. Catterton WZ, Escobedo MB, Sexson WR, Grey ME, Sundell HW, Stahlman MT 1979 Effects of epidermal growth factor on lung maturation in fetal rabbit. Pediatr Res 13:104-108

5. Opleta K, O'Loughlin EV, Shaffer EA, Hayden J, Hollenberg M, Gall DG 1987 Effect of epidermal growth factor on growth and postnatal development of the rabbit liver. Am J Physiol 253:G622-G626

6. Lebenthal E, Leung Y-K 1979 Epidermal growth factor (EGF) and the ontogeny of the gut. J Pediatr Gastroenterol Nutr 6:1-4

7. Gorin PD, Johnson EM 1979 Experimental autoimmune model of nerve growth factor deprivation: effects on developing peripheral sympathetic and sensory neurons. Proc Natl Acad Sci USA 76:5382-5386

8. Raaberg L, Nexø E, Seier Poulsen S, Jørgensen PE 1995 An immunological approach to induction of epidermal growth factor deficiency: induction and characterization of autoantibodies to epidermal growth factor. Pediatr Res 37:169-174

9. Fisher DA, Lakshamanan J 1990 Metabolism and effects of epidermal growth factor and related peptides in mammals. Endocrinol Rev 11:418-442

10. Jørgensen PE, Poulsen SS, Nexø E 1988 Distribution of i.v. administered epidermal growth factor in the rat. Regul Pept 23:161-169

11. Raaberg L, Nexø E, Tollund L, Poulsen SS, Christensen SB, Christensen MS 1990 Epidermal growth factor reactivity in rat milk. Regul Pept 30:149-157

12. Nexø E, Lamberg SI, Hollenberg MD 1981 Comparison of a receptor binding assay with a radioimmunoassay for measuring epidermal growth factor-urogastrone in urine. Scand J Clin Lab Invest 41:577-582

13. Smith PK, Krohn RI, Hermanson GT, Mallia AK, Gartner FH, Provenzano MD, Fujimoto EK, Goeke EK, Olson BJ, Klenk DC 1985 Measurement of protein using bicinchonic acid. Anal Biochem 150:76-85

14. Olsen PS, Nexø E 1983 Quantitation of epidermal growth factor in the rat. Identification and partial characterization of duodenal EGF. Scand J Gastroenterol 18:771-776

15. Nexø E, Olsen PS, Hansen FH 1984 Purification of human epidermal growth factor-urogastrone by immunoaffinity chromatography. In: Peeters $\mathrm{H}$ (ed) Protides of the Biological Fluids. Pergamon Press, New York, pp 1113-1115

16. Raaberg L, Poulsen SS, Nexø E 1991 Epidermal growth factor in the rat lung. Histochemistry 95:471-475

17. Guguen-Guillouzo C, Tichonocky L, Szajnert MF, Kruh J 1980 Changes in some chromatin and cytoplasmic enzymes of perinatal rat hepaocytes during culture. In Vitro 16:1-10

18. Brambell FW 1970 Frontiers of Biology, Vol 18. Elsevier, New York

19. DiAugustine RP, Rosch MJ, Lannon DE, Walker MP, Pratt RM 1987 Evaluation of murine placental degradation and transfere of $\left[{ }^{125} \mathrm{I}\right]$ iodo-epidermal growth factor. Endocrinology 120:1190-1200

20. Tsutsumi O, Oka T 1987 Epidermal growth factor deficiency during pregnancy causes abortion in mice. Am J Obstet Gynaecol 156:241-244

21. Raaberg L, Nexø E, Damsgaard Mikkelsen J, Poulsen SS 1988 Immunohistochemical localization and developmental aspects of epidermal growth factor in the rat. Histochemistry 89:351-356

22. Hoath SB 1986 Treatment of neonatal rats with epidermal growth factor: difference in time and organ response. Pediatr Res 20:468-472

23. Ali P, D'Souza SW, Smart JL 1990 Epidermal growth factor administered in pregnancy has little effect on placenta, fetal, and postnatal growth and development in rats. Biol Neonate 57:318-324

24. Jansson T, Skarland H 1990 Maternally administered epidermal growth factor stimulates fetal growth in the rat. Acta Physiol Scand 138:245-246

25. Whitsett JA, Weaver TE, Lieberman MA, Clark JC, Daugherty C 1987 Differential effects of epidermal growth factor and transforming growth factor-beta on syntheses of $\mathrm{Mr}=35,000$ surfactant-associated protein in fetal lungs. J Biol Chem 262:79087913

26. Warburton D, Seth R, Shum L, Horcher PG, Hall FL, Werb Z, Slavkin HC 1992 Epigenetic role of epidermal growth factor expression and signalling in embryonic mouse lung morphogenesis. Dev Biol 149:123-133

27. Adamson ED, Deller MJ, Warshaw JB 1981 Functional EGF receptors are present on mouse embryo tissues. Nature 291:656-659

28. Nexø E, Kryger-Baggesen N 1990 The receptor for epidermal growth factor is present in human fetal kidney, liver and lung. Regul Pept 30:149-157

29. Walker SR, Williams MC, Benson B 1986 Immunocytochemical localization of major surfactant apoproteins in type II cells, Clara cells and alveolar macrophages of rat lung. J Histochem Cytochem 34:1137-1148

30. Weaver TE, Whitsett JA 1991 Function and regulation of expression of pulmonary surfactant-associated proteins. Biochem J 273:249-264

31. Raaberg L, Nexø E, Buckley S, Luo W, Snead ML, Warburton D 1992 Epidermal growth factor transcription, translation and signal transduction by rat type II pneumocytes in culture. Am J Respir Cell Mol Biol 6:44-49

32. Bertsch S, Marks F 1974 Effect of foetal calf serum and epidermal growth factor on DNA synthesis in explants of chick embryo epidermis. Nature 251:517-519

33. Hoober JK, Cohen S 1966 Epidermal growth factor. I. The stimulation of protein and ribonucleic acid synthesis in the chick embryo epidermis. Biochem Biophys Acta 138:347-356

34. Green MR, Phil D, Couchman JR 1984 Distribution of epidermal growth factor receptor in rat tissues during embryonic skin development, hair formation, and the adult hair growth cycle. J Invest Dermatol 83:118-123

35. Mann BC, Fowler KJ, Gabriel A, Nice EC, Williams EL, Dunn AR 1993 Mice with a null mutation of the TGF- $\alpha$ gene have abnormal skin architecture, wavy hair and curly whiskers and often develop corneal inflammation. Cell 73:249-261

36. Luetteke NC, Qui TH, Peiffer RL, Oliver P, Smithies O, Lee DC 1993 TGF $\alpha$ deficiency results in hair follicle and eye abnormalities in targeted and waved-1 mice. Cell 73:263-278 